BMJ Open Sport \& Exercise Medicine

\title{
Concussion in European professional football: a view of team physicians
}

\author{
Vincent Gouttebarge (D) , ,2,3,4 Imtiaz Ahmad, ${ }^{5}$ Zafar Iqbal, ${ }^{6}$ Emmanuel Orhant, ${ }^{7}$ \\ Craig Rosenbloom, ${ }^{8,9}$ Kristof Sas, ${ }^{10}$ Gino M M J Kerkhoffs ${ }^{1,4,11}$
}

To cite: Gouttebarge V, Ahmad I, Iqbal Z, et al. Concussion in European professional football: a view of team physicians. BMJ Open Sport \& Exercise Medicine 2021;7:e001086. doi:10.1136/ bmjsem-2021-001086

Accepted 28 May 2021
Check for updates

(C) Author(s) (or their employer(s)) 2021. Re-use permitted under CC BY-NC. No commercial re-use. See rights and permissions. Published by BMJ.

For numbered affiliations see end of article.

Correspondence to Dr Vincent Gouttebarge; v.gouttebarge@amsterdamumc. $\mathrm{nl}$

\section{ABSTRACT}

Objectives The objective was to explore the view and thoughts of physicians working in professional football about several aspects (eg, education and use of video footages) likely to enhance concussions' recognition and on-field management.

Methods An observational study based on a crosssectional design by means of an electronic survey was conducted among physicians working for a professional football club in Belgium, England or France.

Results A total of 96 physicians (95\% male; mean age: 44 years) completed the survey. Nearly all participants $(95 \%)$ were in favour of informational sessions about concussion for players or technical staff. Only $5 \%-10 \%$ of the participants mentioned that they had felt pressured by the technical staff or players not to substitute a player with a (potential) concussion. Most participants were in favour of an additional permanent concussion substitution and a temporary concussion substitution. Four out of five participants reported that the availability of instant video footages (side-line) would ease the recognition of concussion.

Conclusion A better recognition and on-field management of concussions in professional football can only be achieved with a holistic approach, including adequate laws of the football game and protocols. Especially, regular education of players and technical staff should be made mandatory while the medical teams should be provided side-line with instant video footages.

\section{INTRODUCTION}

Concussion is induced by biomechanical forces after a direct or indirect (transmitted) blow to the head resulting in temporary neurological impairment. ${ }^{1}$ Concussions are not very common in professional football: incidence ranges between 0.03 and 0.07 concussions per 1000 player hours in men's European professional football, and reaches up to 2.6 concussions per 1000 player hours in women professional football. ${ }^{23}$ Because of the debatable on-field management of recent concussions during high-profile matches and the growing worry for their potential long-term health consequences, concussion management in professional football has received much scrutiny. ${ }^{4-6}$ While the prevention of concussions in professional football

\section{What are the new findings?}

A better recognition and on-field management of concussions in professional football can only be achieved with a holistic approach including adequate laws of the football game and protocols.

- Nearly all enrolled physicians working in professional football are in favour of regular informational sessions about concussion for players or technical staff.

- There is a strong call from physicians working in professional football for the use of instant video footages in order to ease the identification of potential concussive injuries from the sidelines of the field.

- According to physicians working in professional football, the added value of temporary concussion substitutions should be explored as soon as possible.

has always been a priority for its stakeholders, the team physician's ability to recognise and handle a concussion appropriately is central to its successful management in professional football. Following recommendations from its Concussion Expert Group, the International Football Association Board (The IFAB) has recently approved extensive trials with additional permanent substitutions for actual or suspected concussions. This was well received in professional football in the UK as medical staff showed strong support for concussion substitution. ${ }^{7}$ However, the view of football physicians from the UK and other countries about other measures related to concussion recognition and management should be gathered as well. The objective was to explore the view and thoughts of physicians working in professional football about several aspects (eg, education, change in the laws of the football game and use of video footages) likely to enhance concussions' recognition and on-field management.

\section{METHODS \\ Design}

An observational study based on a crosssectional design by means of an electronic survey was conducted. ${ }^{8}$ This study was 
conducted in accordance with the Declaration of Helsinki and the Dutch Personal Data Protection Act. ${ }^{9}$

\section{Participants}

The inclusion criteria for the participants of the study were as follow: (1) being a physician working for a professional football club (eg, first team, academy) in Belgium, England or France; (2) being $\geq 18$ years and (3) able to read and comprehend text in Dutch, English or French.

\section{Survey}

The authors developed a total of 26 questions or statements divided in four distinct sections, namely: (1) 5 questions related to participants' characteristics (eg, 'For how many years are you working in professional football?'); (2) 5 questions and 2 statements related to concussion's education (eg, 'Does your club hold at least once every season an informational session about concussion for the technical staff?', 'An informational session about concussion should be held at least once every season for players'); (3) 8 questions related to concussion's experiences (eg, 'Before/at the start of a season, do you conduct a baseline neurological/neuropsychological assessment with your players?') and (4) 6 questions related to potential changes in concussion's approach (eg, 'Do you think that an additional permanent concussion substitution (in addition to the current 3 or 5 substitutions) would ease to assess and protect a player potentially concussed?'). Questions were answered on different response scales (eg, 'yes, no, I do not know', 5-point Likert scale from 'never' to 'always') while statements were scored on a 4-point Likert scale from 'totally agree' to 'totally disagree'.

\section{Procedures}

Based on all questions, an electronic anonymous survey (available in Dutch, English and French) was compiled (Typeform Professional). Information about the study was sent by email to potential participants by their respective national medical network within professional football in Belgium, England and France. If interested in the study, all participants gave their electronic informed consent and completed anonymously the survey. Data were collected in January 2021.

\section{Statistical analyses}

The statistical software IBM SPSS V.26.0 for Apple Mac was used for data analysis. Descriptive analyses (mean, SD, frequency and/or range) were performed for all survey's questions.

\section{RESULTS}

\section{Participants' characteristics}

A total of 96 physicians gave their electronic informed consent (response rate of $61 \%$ ) and completed the survey. On average, participants (95\% male) were 44 years of age and were working in professional football for 10 years (majority in highest national league).
Participants reported that they saw on average two concussions per season in matches in the team they principally worked with. All participants' characteristics are presented in table 1.

\section{Concussion's education}

While nearly all participants $(93 \%-95 \%)$ were in favour of informational sessions about concussion for players or technical staff, a minority (34\%-39\%) reported that such sessions occurred at their club. Participants mentioned that especially their respective Football Association and their club was responsible for informational sessions about concussion (table 1).

Table 1 Participant characteristics $(\mathrm{N}=96)$ and their view on concussion education

\begin{tabular}{|c|c|}
\hline \multicolumn{2}{|l|}{ Participant characteristics } \\
\hline Age (in years; mean $\pm S D$ ) & $43.7 \pm 11.7$ \\
\hline Gender (male; \%) & 95 \\
\hline $\begin{array}{l}\text { Experience in professional football (in years; } \\
\text { mean } \pm \text { SD) }\end{array}$ & $10.2 \pm 8.5$ \\
\hline \multicolumn{2}{|l|}{ Country (N) } \\
\hline Belgium & 13 \\
\hline England & 24 \\
\hline France & 59 \\
\hline \multicolumn{2}{|l|}{ Team level of play (top league; \%) } \\
\hline Highest national league ${ }^{\star}$ & 56 \\
\hline Second highest national league $†$ & 22 \\
\hline Youth academy & 14 \\
\hline National team & 8 \\
\hline Number of concussions per season (mean \pm SD) & $2.0 \pm 1.1$ \\
\hline \multicolumn{2}{|l|}{ Concussion education } \\
\hline \multicolumn{2}{|l|}{ Educational session for players (\%) } \\
\hline Yes yearly & 34 \\
\hline In favour to it at least once every season & 95 \\
\hline $\begin{array}{l}\text { Responsibility by the national football } \\
\text { association }\end{array}$ & 46 \\
\hline Responsibility by the club & 39 \\
\hline \multicolumn{2}{|l|}{ Educational session for technical staff (\%) } \\
\hline Yes yearly & 39 \\
\hline In favour to it at least once every season & 93 \\
\hline $\begin{array}{l}\text { Responsibility by the national football } \\
\text { association }\end{array}$ & 45 \\
\hline Responsibility by the club & 46 \\
\hline \multicolumn{2}{|l|}{ Educational session for medical staff (\%) } \\
\hline $\begin{array}{l}\text { Responsibility by the national football } \\
\text { association }\end{array}$ & 70 \\
\hline
\end{tabular}

*Eerste klasse A, Premier League, Ligue 1, Super League voor Vrouwen, Women's Super League, Division 1 Féminine.

†Eerste klasse B, Championship, Ligue 2.

$\mathrm{N}$, number of participants.; 
Table 2 Concussion's experiences and potential changes in concussion's approach

\begin{tabular}{|c|c|}
\hline \multicolumn{2}{|l|}{ Concussion experiences } \\
\hline \multicolumn{2}{|l|}{$\begin{array}{l}\text { Baseline neurological/neuropsychological assessment } \\
(\%)\end{array}$} \\
\hline No & 63 \\
\hline Yes with SCAT5 & 33 \\
\hline Yes with ImPACT & 4 \\
\hline Club doctor in charge for substitution or not (\%) & 97 \\
\hline \multicolumn{2}{|l|}{ Under pressure to not substitute a player (\%) } \\
\hline Always/often by technical staff & 10 \\
\hline Always/often by players & 5 \\
\hline \multicolumn{2}{|l|}{ Potential changes } \\
\hline Not enough time for player's assessment (\%) & 33 \\
\hline $\begin{array}{l}\text { In favour of additional permanent concussion } \\
\text { substitution (\%) }\end{array}$ & 78 \\
\hline In favour of temporary concussion substitution (\%) & 83 \\
\hline $\begin{array}{l}\text { In favour of permanent substitution in case of bleeding } \\
\text { head injury (\%) }\end{array}$ & 54 \\
\hline $\begin{array}{l}\text { Added value of the availability of instant video } \\
\text { footages (\%) }\end{array}$ & 79 \\
\hline $\begin{array}{l}\text { Added value of the assistance of an independent } \\
\text { physician (\%) }\end{array}$ & 37 \\
\hline
\end{tabular}

ImPACT, Immediate Post-Concussion Assessment and Cognitive Test; SCAT5, Sport Concussion Assessment Tool 5.

\section{Concussion's experiences}

During their recent seasons in professional football, $97 \%$ of the participants took ultimately the decision to substitute or not a player with a (suspected) concussion, while $5 \%-10 \%$ mentioned that they had felt pressured by the technical staff or players not to substitute a player with a (potential) concussion. All participants' experiences are presented in table 2.

\section{Potential changes in concussion's approach}

Most participants were in favour of an additional permanent concussion substitution (in addition to the regular substitutions; $78 \%$ ) and a temporary concussion substitution $(83 \%)$. Four out of five participants reported that the availability of instant video footages (side-line) would ease the recognition of concussion (table 2).

\section{DISCUSSION}

This study explored the view of physicians working in professional football about how to enhance concussions' recognition and on-field management. The main findings are that regular education of players and technical staff should be made mandatory while the medical teams should be provided side-line with instant video footages.

\section{Needs to educate players and staff}

The on-field management of recent concussions during high-profile football matches have emphasised how important it is to thoroughly educate players as well as members of the technical and medical teams. With that regard, nearly all physicians enrolled in our study were in favour to an informational session about concussion at least once every season for players and the members of the technical team. As this does not occur systematically across leagues and clubs, the authors strongly recommend the alliance of national football stakeholders (football association, league, club and players' union) in order to facilitate concussion education. This has been shown to lead to better attitude towards concussion, such concussion education should even be made mandatory in professional football. ${ }^{10}$ This would follow other sports such as in English rugby union in which the yearly completion of an educational concussion module has been made compulsory for many years.

\section{Current experience of medical teams}

Physicians enrolled in our study estimated that they were seeing two concussions per season in matches (equivalent of 2.4/1000 hours of match play; consistent across countries), which is higher than recently reported elsewhere (eg, 1.2/1000 hours of match play) ${ }^{11}{ }^{12}$ It is worth mentioning that concussion remains underreported in professional football by comparison to other contact sports, with rates up to 20 concussions per 1000 hours of match play. ${ }^{13}$ A positive finding was that the decision to substitute or not a player with a (suspected) concussion was taken nearly all the time (97\%) by the medical team. Such an autonomy and/or leadership is important for any clinical decision but even more in the context of concussion: it is important that players and/or technical staff do not interfere in the medical team's decision. Another positive finding was that only few physicians $(<10 \%)$ reported having been pressured by either players or technical staff to not to substitute a player with a (potential) concussion. Such a positive finding eliminates the main argument put forward recently to change the laws of the football game and introduce an additional permanent concussion substitution. ${ }^{14}$

\section{Change in the laws of the football game}

In December 2020, The IFAB approved to trial the use of one or two additional permanent concussion substitutions (in addition to the current three or five substitutions). Such a change in the laws of the football game is believed to put less pressure on the medical team to not to substitute a player with a (potential) concussion but as previously mentioned, nearly all physicians $(>90 \%)$ working in Belgium, English and French professional football did not feel pressured by either plavers or technical staff. Nonetheless, and despite that this change does not provide physicians with more time for their assessment, almost four out of five physicians were in favour of additional permanent concussion substitution. More than $80 \%$ of the physicians reported that temporary concussion substitution would ease to assess and protect a player potentially concussed. Such temporary concussion substitution has been used in many high-speed collision 
sports with high rates of concussions (eg, rugby union) but trialling such a change in the laws of the football game has been withheld by The IFAB.

\section{Changes in concussion's protocols}

Next to the laws of the football game set by The IFAB, concussion's protocols set by competition organisers (eg, FIFA and national leagues) are essential to recognise and manage concussions optimally. With that regard, there is a strong call from physicians for the use of instant video footages as the identification of potential concussive injuries is often impaired from the sidelines of the field. International consensus definitions of video signs of concussion have been recently established by major international sporting codes but surprisingly football did not participate. ${ }^{15}$ To protect players optimally, the authors would also like to acknowledge that the return to play protocols in professional football should prevent any player concussed over a weekend to return to play at the subsequent mid-week match.

\section{CONCLUSION}

A better recognition and on-field management of concussions in professional football can only be achieved with a holistic approach, including adequate laws of the football game and protocols. Especially, regular education of players and technical staff should be made mandatory while the medical teams should be provided side-line with instant video footages. The added value of temporary concussion substitutions should be explored as soon as possible.

\section{Author affiliations \\ ${ }^{1}$ Amsterdam UMC, University of Amsterdam, Department of Orthopaedic Surgery, Amsterdam Movement Sciences, Meibergdreef 9, Amsterdam, Netherlands ${ }^{2}$ Section Sports Medicine, University of Pretoria, Pretoria, South Africa ${ }^{3}$ FIFPRO (Football Players Worldwide), Hoofddorp, Netherlands ${ }^{4}$ Amsterdam Collaboration on Health \& Safety in Sports (ACHSS), Amsterdam UMC IOC Research Center of Excellence, Amsterdam, Netherlands \\ ${ }^{5}$ Medical Department, Queens Park Rangers Football and Athletic Club, London, UK ${ }^{6}$ Medical Department, Crystal Palace Football Club, London, UK \\ ${ }^{7}$ French Football Federation (FFF), Clairefontaine Medical Centre, FIFA Medical Center of Excellence, Clairefontaine, France \\ ${ }^{8}$ The Football Association, Technical Directorate, Burton-upon-Trent, UK \\ ${ }^{9}$ Queen Mary University of London, London, UK \\ ${ }^{10}$ Medical Department, Royal Sporting Club Anderlecht, Brussels, Belgium \\ ${ }^{11}$ Academic Center for Evidence based Sports medicine (ACES), Amsterdam Movement Sciences, Amsterdam, Netherlands}

\section{Twitter Vincent Gouttebarge @VGouttebarge}

Acknowledgements We greatly thank all participants for their participation in the study.

Contributors All authors were involved in the design of the study, were involved in the data interpretation, and read and approved the final version of the manuscript. VG was responsible for data collection, for the data analysis and drafted the initial version of the manuscript, with critical review provided by all authors.

Funding The authors have not declared a specific grant for this research from any funding agency in the public, commercial or not-for-profit sectors.
Competing interests None declared.

Patient consent for publication Not required.

Ethics approval Ethical approval for the study was provided by the Medical Ethics Review Committee of the Amsterdam University Medical Center, location Academic Medical Center (W20_541 \# 20.600; Amsterdam, the Netherlands).

Provenance and peer review Not commissioned; externally peer reviewed.

Open access This is an open access article distributed in accordance with the Creative Commons Attribution Non Commercial (CC BY-NC 4.0) license, which permits others to distribute, remix, adapt, build upon this work non-commercially, and license their derivative works on different terms, provided the original work is properly cited, appropriate credit is given, any changes made indicated, and the use is non-commercial. See: http://creativecommons.org/licenses/by-nc/4.0/.

\section{ORCID iD}

Vincent Gouttebarge http://orcid.org/0000-0002-0126-4177

\section{REFERENCES}

1 McCrory P, Meeuwisse W, Dvořák J, et al. Consensus statement on concussion in sport-the $5^{\text {th }}$ international conference on concussion in sport held in Berlin, October 2016. Br J Sports Med 2017;51:838-47.

2 Waldén M, Hägglund M, Orchard J, et al. Regional differences in injury incidence in European professional football. Scand J Med Sci Sports 2013;23:424-30.

3 Dvorak J, McCrory P, Kirkendall DT. Head injuries in the female football player: incidence, mechanisms, risk factors and management. Br J Sports Med 2007;41 Suppl 1:i44-6.

4 Gouttebarge V, Aoki H, Lambert M, et al. A history of concussions is associated with symptoms of common mental disorders in former male professional athletes across a range of sports. Phys Sportsmed 2017;45:443-9.

5 Cunningham J, Broglio SP, O'Grady M, et al. History of sport-related concussion and long-term clinical cognitive health outcomes in retired athletes: a systematic review. J Ath/ Train 2020;55:132-58.

6 Walton SR, Kerr ZY, Brett BL, et al. Health-Promoting behaviours and concussion history are associated with cognitive function, moodrelated symptoms and emotional-behavioural dyscontrol in former NFL players: an NFL-LONG study. Br J Sports Med 2021. doi:10.1136/ bjsports-2020-103400. [Epub ahead of print: 04 Jan 2021].

7 Rosenbloom C, Broman D, Chu W. Sport-Related concussion practices of medical team staff in elite football in the United Kingdom, a pilot study. Science and Medicine in Football 2021;9:1-9.

8 Woodward M. Epidemiology: study design and data analysis. Boca Raton: CRC Press, 2014.

9 World Medical Association. World Medical association Declaration of Helsinki: ethical principles for medical research involving human subjects. JAMA 2013;310:191-4.

10 Gouttebarge V, Cowie C, Goedhart E, et al. Educational concussion module for professional footballers: from systematic development to feasibility and effect. BMJ Open Sport Exerc Med 2019;5:e000490.

11 Vedung F, Hänni S, Tegner Y, et al. Concussion incidence and recovery in Swedish elite soccer - Prolonged recovery in female players. Scand J Med Sci Sports 2020;30:947-57.

12 Cassoudesalle H, Laborde B, Orhant E, et al. Video analysis of concussion mechanisms and immediate management in French men's professional football (soccer) from 2015 to 2019. Scand J Med Sci Sports 2021;31:465-72.

13 England Professional Rugby Injury Surveillance Project Steering Group. Rugby players England professional rugby injury surveillance project: season report 2018-2019. Twickenham: Rugby Football Union, 2020.

14 International football association board (the IFAB). Available: https:// www.theifab.com/news/annual-business-meeting-2020 [Accessed 7 May 2021].

15 Davis GA, Makdissi M, Bloomfield P, et al. International consensus definitions of video signs of concussion in professional sports. $\mathrm{Br} \mathrm{J}$ Sports Med 2019;53:1264-7. 